\title{
Comfort Behavior of Unconventional Natural Fiber Based Union Fabrics
}

\author{
Kavita Rani1, Lalit Jajpura1, B. K. Behera ${ }^{2 *}$ \\ ${ }^{1}$ Department of Fashion Technology, BPS Mahila Vishwavidyalaya, Khanpur Kalan, Sonipat, Haryana, India \\ ${ }^{2}$ Department of Textile Technology, Indian Institute of Technology, Delhi, India \\ Email: kavitalakhlan@gmail.com, jajpural@nitj.ac.in, ‘behera@textile.iitd.ac.in
}

How to cite this paper: Rani, K., Jajpura, L. and Behera, B.K. (2019) Comfort Behavior of Unconventional Natural Fiber Based Union Fabrics. Journal of Textile Science and Technology, 5, 125-133.

https://doi.org/10.4236/jtst.2019.54011

Received: September 12, 2019

Accepted: November 16, 2019

Published: November 19, 2019

Copyright (c) 2019 by author(s) and Scientific Research Publishing Inc. This work is licensed under the Creative Commons Attribution International License (CC BY 4.0).

http://creativecommons.org/licenses/by/4.0/

\begin{abstract}
To fulfill the sustainability need of today's comfort conscious consumers, an attempt has been made in this research study to explore the possibilities of producing high-quality apparel fabrics using unconventional fiber fabrics and their union fabrics. Unconventional natural fibers such as banana, hemp, linen and ramie and also their union fabrics with cotton were used. Union fabrics have different fiber content in warp and weft directions. A comparative study was made on the comfort behavior of these fabrics to evaluate their comfort performance. The properties of these fabrics were evaluated and compared under air permeability, moisture management, thermal properties, low-stress mechanical properties, etc. Unconventional fiber fabrics showed better results in many cases and thus were comparable with $100 \%$ cotton fabrics.
\end{abstract}

\section{Keywords}

Comfort, Low-Stress Mechanical Properties, Fabric Hand, Union fabric, Air Permeability

\section{Introduction}

With the advancement in our time, people have placed a great emphasis on environment-friendly materials and processes. This trend results in an encouragement to use and develop fibers that can be obtained or manufactured from renewable sources like natural fibers as a substitute for conventional synthetic fibers that are based on petroleum. Even cotton fiber is now considered as noneco-friendly fiber as it requires large quantity of chemicals, pesticides along with water. Unconventional natural fibers such as hemp, ramie, flax, sisal, kenaf, etc. can be used as an alternate to cotton and other synthetic fibers. These alternative 
fibers include banana fiber obtained from pseudo-stem of banana plant, pineapple fibers obtained from leaves, sugarcane fibers obtained from the sugarcane stalks, etc. and some other bast fibers obtained with almost no use of pesticides and chemicals include hemp, ramie, flax, sisal, kenaf, etc. [1]. These fibers are present in abundance all over India but still neglected everywhere. These fibers have potential to become useful textile fibers. Along with abundant availability, these fibers possess characteristics like elegance in aesthetic appeal, comfort in wear and many other utility performances as peruse in different applications including clothing.

Woven designed fabrics with eco-friendly fiber are more in demand. Nowadays consumers are fashion and health-conscious so that they switch towards the eco-friendly fabrics [2]. One of the most important aspects of clothing and apparels is comfort. Clothing comfort is mainly associated with three common aspects such as psychological, tactile and thermal [3]. Psychological comfort is mainly related to the aesthetics of the clothing and fashion trends prevailing in a particular society and has no dependence on fabric's properties quantitatively. Tactile comfort majorly depends upon the interaction between the fabric and skin during wear [4]. It deals with the mechanical properties and surface characteristics of fabric. However, thermal comfort is a measure of fabric's ability to maintain wearer's skin temperature and deals with fabric's transmission behaviors, namely thermal insulation or conductivity, water vapor or liquid water transmission and air permeability [5] [6].

In this research, efforts are being made to explore the possibilities of producing high-quality apparel fabric from unconventional natural fibers under industrial production environment. A comparative study was made on the low-stress mechanical properties, fabric hand and thermal comfort of banana, hemp, linen and ramie fabrics and their respective union fabrics with cotton [7] [8]. Union fabrics are the fabrics where the fiber content is different in the warp and weft direction.

\section{Materials and Methods}

\subsection{Materials}

For this research, the four unconventional fibers namely banana, hemp, linen and ramie are used. Cotton is used as reference fiber for comparison of respective fabric properties. Yarn samples of $30 \mathrm{Ne}$ were developed from the above mentioned five fibers under industrial production conditions and accordingly used for fabric development.

\subsection{Methods}

\subsubsection{Fabric Sample Development}

The nine grey fabric samples were prepared in a weaving mill under controlled manufacturing conditions using construction parameters as given in Table 1. The construction parameters were taken to maintain fabric areal density at $145 \pm$ $10 \mathrm{~g} / \mathrm{m}^{2}$ taking into account the manufacturing constraints in the mill. 
Table 1. Constructional parameters of fabric samples.

\begin{tabular}{ccccccc}
\hline Code & Fabric sample & Warp type & Weft type & Weave & $\begin{array}{c}\text { Weight } \\
\left(\mathrm{g} / \mathrm{m}^{2}\right)\end{array}$ & $\begin{array}{c}\text { Thickness } \\
(\mathrm{mm})\end{array}$ \\
\hline C & $100 \%$ Cotton & $100 \%$ Cotton & $100 \%$ Cotton & Plain & 143 & 0.24 \\
B & $100 \%$ Banana & $100 \%$ Banana & $100 \%$ Banana & Plain & 145 & 0.26 \\
H & $100 \%$ Hemp & $100 \%$ Hemp & $100 \%$ Hemp & Plain & 136 & 0.21 \\
L & $100 \%$ Linen & $100 \%$ Linen & $100 \%$ Linen & Plain & 141 & 0.26 \\
R & $100 \%$ Ramie & $100 \%$ Ramie & $100 \%$ Ramie & Plain & 138 & 0.22 \\
CB & Cotton-Banana Union Fabric & $100 \%$ Cotton & $100 \%$ Banana & Plain & 147 & 0.25 \\
CH & Cotton-Hemp Union Fabric & $100 \%$ Cotton & $100 \%$ Hemp & Plain & 139 & 0.20 \\
CL & Cotton-Linen Union Fabric & $100 \%$ Cotton & $100 \%$ Linen & Plain & 151 & 0.24 \\
CR & Cotton-Ramie Union Fabric & $100 \%$ Cotton & $100 \%$ Ramie & Plain & 144 & 0.22 \\
\hline
\end{tabular}

\subsubsection{Chemical Processing of Fabrics}

The chemical pretreatment of all the fabrics was carried out in industry maintaining standard parameter used in commercial production of cotton fabric. The sequence of chemical processes is as follows:

Desizing $\rightarrow$ Scouring $\rightarrow$ Bleaching $\rightarrow$ Neutralization $\rightarrow$ Stentering $\rightarrow$ Calendering $\rightarrow$ Folding

\subsubsection{Evaluation of Yarn Properties}

Yarn diameter was measured using projection microscope at 50 random places along the length of the yarn. The average of the reading is reported as yarn diameter. Yarn count was measured by weighing known length of yarn on an electronic balance.

\subsubsection{Evaluation of Fabric Constructional Parameters}

All the fabric samples were measured for physical properties such as thread density, fabric mass per unit area and thickness. Fabric thread density was calculated by counting number of yarns per $\mathrm{cm}$ in warp as well as weft directions using a pick glass. Mass per unit area of the fabric samples was evaluated as per IS 1964-2001 method. A circular sample of $11.3 \mathrm{~cm}$ diameter was cut using a paramount round cutter and then weighted on electronic balance to calculate gram per meter square $\left(\mathrm{g} / \mathrm{m}^{2}\right)$ of gram. Fabric thickness was measured on thickness tester under $20 \mathrm{gf} / \mathrm{cm}^{2}$ pressure and the average of 5 readings was taken.

\subsubsection{Evaluation of Fabric Air Permeability}

Air permeability of all the fabric samples was measured on Textest FX 3300 air permeability tester according to standard BS 5636. The instrument measures the volume of air passing through the fabric per unit area per unit time. The $100 \mathrm{~Pa}$ air pressure was maintained, and the test area was $5.08 \mathrm{~cm}^{2}$.

\subsubsection{Evaluation of Fabric Thermal Insulation Property}

The thermal insulation was evaluated on Thermolabo thermal tester. The Kawabata evaluation system (KES FB7-II) was used to measure the heat flow resis- 
tance or thermal insulation value. The sample of $20 \mathrm{~cm} \times 20 \mathrm{~cm}$ dimension with a test area of $10 \mathrm{~cm} \times 10 \mathrm{~cm}$ was used. The testing was done using Dry contact method with air velocity of $30 \mathrm{~cm} / \mathrm{s}$.

\subsubsection{Evaluation of Fabric Relative Moisture Vapor Permeability}

The moisture vapor diffusion rate through the fabric is determined using LABTHINK MVTR tester that works according to the simple dish method, similar to ASTM E96-80. The test sample is placed over a water dish having $33 \mathrm{~cm}^{2}$ area and $7.5 \mathrm{~cm}$ diameter. The test conditions were maintained at $80 \%$ humidity and $38^{\circ} \mathrm{C}$ temp inside the instrument. Dry air is circulated at an interval of $10 \mathrm{~min}$. A vibration-free turntable platform that can accommodate eight dishes rotates at uniform speed. All dishes are exposed to the same average ambient condition during the test. The rate of moisture vapor loss (MVTR) is calculated in units' $\mathrm{g} / \mathrm{m}^{2} / 24 \mathrm{hr}$. A higher MVTR value advocates a greater passage of moisture vapor through the material.

\subsubsection{Evaluation of Fabric Moisture Management}

The multi-dimensions liquid moisture transport properties come under moisture management properties of the fabrics and are evaluated on M290 MMT (Moisture Management Tester) SDL Atlas Inc. (Rock Hill, SC) made in accordance with AATCC Test Method 195-2009 (Liquid Moisture Management Properties of Textile Fabrics). Five specimens of size $8 \times 8 \mathrm{~cm}$ were tested for each sample. Moisture management parameters like absorption rate, one way transport capacity (or OWTC), spreading speed and overall moisture management capacity (OMMC) were analyzed and reported in this study.

\subsubsection{Evaluation of Fabric Low stress Mechanical Properties and Fabric Hand}

The Kawabata Evaluation System was used to measure fabric low stress mechanical properties at standard conditions prescribed for apparel fabric. KES system consists of four different modules for different testing e.g. KES-FB1 for tensile and shear tests, KES-FB2 for bending tests, KES-FB3 for compression properties testing and KES-FB4 for testing surface properties. Total 16 parameters describing fabric mechanical properties were evaluated from the instrumental outputs. The "primary hand values" contributing to specific comfort aspects of the fabric and then "total hand value" were calculated by the software using Kawabata equation [9].

\section{Results and Discussion}

\subsection{Yarn Properties}

From the results shown in Table 2, it is evident that banana yarn is the thickest of all yarns while ramie and linen yarns have smaller diameter for similar linear density. This is mainly due to low density and bulky structure of light weight banana fibers compared to all other natural fibers used in this work. 
Table 2. Yarn properties.

\begin{tabular}{ccc}
\hline Fiber Type & Yarn Diameter $(\mathrm{mm})$ & Yarn Fineness $(\mathrm{Ne})$ \\
\hline Banana & 0.21 & 27 \\
Hemp & 0.20 & 28 \\
Linen & 0.16 & 28 \\
Ramie & 0.15 & 29 \\
Cotton & 0.17 & 30 \\
\hline
\end{tabular}

\subsection{Air Permeability Behavior of Fabrics}

The air permeability of different unconventional fiber fabrics and their respective union fabrics with cotton were studied to ascertain their physiological comfort. The outcomes of the test are listed in Table 3. The results show that pure linen fabrics permit more air to pass through them, compared with pure cotton and all union fabrics. The trend is followed by hemp, ramie and then banana. The reason for higher permeability in case of pure fabrics of unconventional natural fiber fabrics can be attributed to less hairiness in these yarns due to longer fiber length than cotton. These fibers are smoother, circular and coarser than cotton fibers also favor an easy passage to air through the yarn. Also the larger diameter of banana yarn gives high cover of the fabric which prevents transmission of air through the banana fabric [10].

\subsection{Thermal Insulation Property of Fabrics}

For comfort body heat should be transmitted away from the body to the outer side of the clothing. This dry heat transmission occurs through conduction, convection and radiation. The mechanism of heat transmission through a fabric depends on its constituent fiber type, fiber arrangement, fabric bulk density, thickness, and the compressibility of the fabric structure [11]. Cellulosic fiber fabrics are well known for their excellent thermal conductivity. Here, an attempt has been made to compare the thermal behavior of various cellulosic fabrics including union as well as pure fabrics with $100 \%$ cotton. The results for comparative analysis of thermal insulation value (TIV) are listed in Table 3. From the results it can be seen that fabric samples containing cotton indicate thermal insulation values on higher side as compared to pure fabrics of unconventional fibers presumably due to the structure of cotton fiber. Cotton fiber contains hollow lumen and twists causing more air entrapping in yarn. Whereas, the fibers of hemp, linen and ramie are smooth, straight and contain almost no lumen [12].

\subsection{Water Vapor Permeability of Fabrics}

Moisture and water vapor transmission plays a very important role in governing the physiological comfort of apparel fabrics. This is related to the moisture vapor transmission through the fabric. This decides the extent of comfort the wearer feels in a sweating or similar condition. The results of moisture vapor transmission 
Table 3. Results of fabric properties.

\begin{tabular}{ccccc}
\hline \multirow{2}{*}{$\begin{array}{c}\text { Sample } \\
\text { code }\end{array}$} & Weight & Air Permeability & MVTR & TIV \\
\cline { 2 - 5 }$\left(\mathbf{g} / \mathrm{m}^{2}\right)$ & $\left(\mathrm{cm}^{3} / \mathrm{cm}^{2} / \mathrm{s}\right)$ & $\left(\mathrm{g} / \mathrm{m}^{2} /\right.$ day $)$ & $(\%)$ \\
\hline C & 143 & 8.85 & 5128.20 & 3.27 \\
B & 153 & 52.78 & 6414.25 & 2.03 \\
CB & 150 & 11.74 & 6223.70 & 4.80 \\
H & 136 & 64.95 & 6566.97 & 1.61 \\
CH & 137 & 10.11 & 6393.15 & 4.61 \\
L & 141 & 91.34 & 6295.70 & 1.67 \\
CL & 149 & 12.02 & 5728.81 & 3.97 \\
R & 135 & 56.48 & 6827.34 & 1.61 \\
CR & 137 & 10.21 & 6430.97 & 4.91 \\
\hline
\end{tabular}

rate (MVTR) are listed in Table 3. The findings reveal that all the pure fabrics of unconventional fibers and their respective union fabrics have increased volumes of moisture vapor transmission as compared to the reference cotton sample. This behavior can be attributed to the hygroscopic nature of the fibers used. Also the fiber properties like diameter, rigidness and cross-section play an essential role in deciding the extent of openness of structure that will be responsible for better moisture vapor transmission. The higher values of MVTR indicates that these fabrics can transfer liquid moisture (sensible sweating) very easily and quickly from next-to-skin (inner side) to the outer surface.

\subsection{Fabric Moisture Management Properties}

The findings compiled in Table 4 reveal that all the pure fabrics of unconventional fibers and their respective union fabrics have increased values of Accumulative one-way transport index (OWTC) as compared to the reference cotton sample. Generally fabrics which possess high OWTC values indicate that the liquid (sweat) can be quickly transferred from the inner surface next to the skin to the outside surface. Also it will be spread quickly over the fabric bottom surface with a large wetted area. This large area spread of liquid help its quick evaporation into the environment. This behavior can be attributed to the hygroscopic nature of the fibers used. Also the fiber properties like diameter, rigidness and cross-section play a major role in deciding. Hemp fabrics show a relatively higher OMTC values and bottom spreading speed. This indicates that hemp fabrics can manage liquid moisture very efficiently. The sweat will quickly transmit to the outer side of such clothing and so will be evaporated by larger spreading in no time. The bottom water radius is also higher than top in fabrics containing hemp. The fabrics containing linen falls in the next position after hemp in such type of overall moisture management.

\subsection{Low Stress Mechanical Properties and Fabric Hand}

The 16 parameters related to low stress mechanical properties of the fabrics measured on Kawabata Evaluation Systems [13] are reported in Table 5 and Table 6 with their standard notations. 
Table 4. Results of moisture management properties.

\begin{tabular}{|c|c|c|c|c|c|c|c|c|c|c|}
\hline \multirow{3}{*}{$\begin{array}{l}\text { Sample } \\
\text { Code }\end{array}$} & \multicolumn{2}{|c|}{ Wetting Time } & \multicolumn{2}{|c|}{ Absorption Rate } & \multicolumn{2}{|c|}{ Max water Radius } & \multicolumn{2}{|c|}{ Spreading speed } & \multirow{2}{*}{$\begin{array}{c}\text { Accumulative } \\
\text { one-way transport } \\
\text { index }\end{array}$} & \multirow{3}{*}{ OMMC } \\
\hline & Top & Bottom & Top & Bottom & Top & Bottom & Top & Bottom & & \\
\hline & $(\mathrm{Sec})$ & $(\mathrm{Sec})$ & $(\% / \mathrm{sec})$ & $(\% / \mathrm{sec})$ & $(\mathrm{mm})$ & $(\mathrm{mm})$ & $(\mathrm{mm} / \mathrm{sec})$ & $(\mathrm{mm} / \mathrm{sec})$ & (\%) & \\
\hline $\mathrm{C}$ & 2.70 & 2.66 & 75.06 & 94.27 & 30 & 30 & 6.44 & 6.25 & 394.26 & 0.9588 \\
\hline B & 2.68 & 2.64 & 56.53 & 89.36 & 25 & 25 & 5.79 & 5.64 & 471.52 & 0.9667 \\
\hline $\mathrm{H}$ & 3.20 & 3.26 & 13.36 & 78.80 & 20 & 25 & 2.31 & 5.46 & 995.37 & 0.9412 \\
\hline $\mathrm{L}$ & 2.40 & 2.32 & 40.47 & 91.67 & 30 & 30 & 5.89 & 6.74 & 561.66 & 0.9395 \\
\hline $\mathrm{R}$ & 2.24 & 2.08 & 24.23 & 65.95 & 27.5 & 27.5 & 5.77 & 5.68 & 758.45 & 0.9054 \\
\hline $\mathrm{CB}$ & 3.08 & 2.96 & 48.90 & 88.32 & 25 & 25 & 4.82 & 5.09 & 559.94 & 0.9676 \\
\hline $\mathrm{CH}$ & 2.96 & 2.20 & 40.27 & 94.68 & 27.5 & 30 & 6.48 & 6.98 & 676.00 & 0.9852 \\
\hline CL & 5.29 & 5.77 & 30.01 & 96.55 & 15 & 27.5 & 2.41 & 4.55 & 1085.88 & 0.9321 \\
\hline CR & 3.76 & 3.72 & 49.04 & 73.61 & 20 & 30 & 2.80 & 4.07 & 889.24 & 0.9132 \\
\hline
\end{tabular}

Table 5. KES test results of tensile, bending and shear properties.

\begin{tabular}{ccccccccc}
\hline \multirow{2}{*}{ Sample } & LT & WT & RT & B & $2 \mathrm{HB}$ & G & $2 \mathrm{HG}$ & $2 \mathrm{HG}_{5}$ \\
\cline { 2 - 8 } & & gf·cm $/ \mathrm{cm}^{2}$ & $\%$ & gf $\cdot \mathrm{cm}^{2} / \mathrm{cm}$ & gf $\cdot \mathrm{cm} / \mathrm{cm}$ & gf/cm/degree & gf/cm & gf/cm \\
\hline C & 0.9965 & 0.1200 & 75.365 & 0.1626 & 0.5161 & 4.195 & 6.150 & 14.835 \\
B & 1.0290 & 0.5250 & 44.170 & 0.0949 & 0.0921 & 1.515 & 2.980 & 6.810 \\
CB & 1.0705 & 0.1100 & 85.090 & 0.1794 & 0.1101 & 3.145 & 5.110 & 13.305 \\
H & 0.9150 & 0.1250 & 107.475 & 0.3285 & 0.1858 & 1.445 & 0.655 & 9.470 \\
CH & 1.0410 & 0.2350 & 52.965 & 0.0789 & 0.0810 & 3.315 & 6.570 & 11.485 \\
L & 0.8165 & 0.1800 & 74.480 & 0.3738 & 0.1427 & 0.610 & 0.610 & 2.630 \\
CL & 1.0095 & 0.1000 & 85.110 & 0.1960 & 0.1399 & 4.775 & 9.015 & 16.435 \\
R & 1.0825 & 0.0950 & 107.120 & 0.1858 & 0.2299 & 2.620 & 3.750 & 14.780 \\
CR & 1.0095 & 0.1000 & 85.110 & 0.1960 & 0.1399 & 4.775 & 9.015 & 16.435 \\
\hline
\end{tabular}

It may be observed that the bending and shear hysteresis of cotton and cotton rich union fabrics are significantly higher than other fabrics. The tensile resiliency values of hemp and ramie fabrics are also significantly higher than other fabrics. Tensile linearity of all cellulosic fibers is almost similar; the same is also observed in case of low stress compressibility. This actually falls in the logic that at low stress levels both tensile and compression results behave alike. From surface properties point of view, banana and linen fabrics exhibit significantly higher geometrical roughness (SMD) due to higher hairiness and surface roughness of these two yarns.

The THV of the fabric samples is estimated with the help of various primary hand values using the Kawabata-Niwa equations by KES system and the results are displayed in Figure 1. It may be observed that the linen fabric gives the 
Table 6. KES test results of surface and compression properties.

\begin{tabular}{|c|c|c|c|c|c|c|c|c|}
\hline Sample & LC & WC & $\mathrm{RC}$ & MIU & MMD & SMD & $\mathrm{T}$ & $\mathrm{W}$ \\
\hline & & $\mathrm{gf} \cdot \mathrm{cm} / \mathrm{cm}^{2}$ & $\%$ & & & micron & $\mathrm{mm}$ & $\mathrm{mg} / \mathrm{cm}^{2}$ \\
\hline C & 1.078 & 0.037 & 32.080 & 0.177 & 0.0068 & 2.40 & 0.184 & 13.900 \\
\hline B & 1.138 & 0.037 & 52.700 & 0.160 & 0.0081 & 6.86 & 0.279 & 15.300 \\
\hline $\mathrm{CB}$ & 0.990 & 0.037 & 31.910 & 0.163 & 0.0155 & 4.59 & 0.208 & 15.100 \\
\hline $\mathrm{H}$ & 0.999 & 0.036 & 59.770 & 0.160 & 0.0149 & 3.44 & 0.219 & 13.600 \\
\hline $\mathrm{CH}$ & 1.138 & 0.052 & 36.280 & 0.157 & 0.0082 & 4.36 & 0.249 & 14.700 \\
\hline $\mathrm{L}$ & 0.994 & 0.036 & 36.830 & 0.145 & 0.0120 & 8.92 & 0.238 & 14.100 \\
\hline $\mathrm{CL}$ & 1.081 & 0.029 & 33.210 & 0.153 & 0.0084 & 3.55 & 0.347 & 14.400 \\
\hline $\mathrm{R}$ & 0.891 & 0.030 & 28.940 & 0.160 & 0.0152 & 4.00 & 0.191 & 13.800 \\
\hline CR & 1.081 & 0.029 & 33.210 & 0.153 & 0.0084 & 3.55 & 0.347 & 14.400 \\
\hline
\end{tabular}

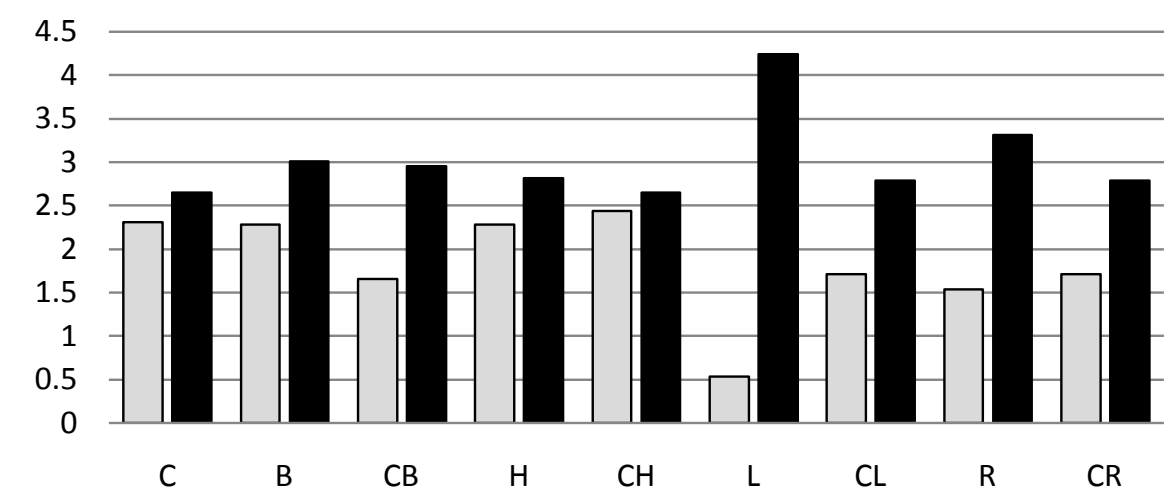

Figure 1. Total hand values (THV) of different fabric samples.

highest THV for summer and lowest THV for winter applications. This behavior is reflected in its constituent low stress mechanical properties where it found that both bending and shear hysteresis are significantly lower than other fabrics. The results also depict that almost all the fabric samples exhibit higher THV for summer applications as compared to winter due to obvious reason of their suitability as a cellulosic fiber predominantly meant for tropical and sub-tropical climate. The values of summer THV of all pure unconventional fiber based fabrics and their respective union fabrics are either comparable or better than $100 \%$ cotton. This trend strongly advocates the possibility of unconventional fiber fabrics to be used as an apparel fabric for summers.

\section{Conclusions}

The unconventional fiber fabrics allow more air to pass through as compared to $100 \%$ cotton fabric of similar areal density.

The unconventional fiber fabrics and their union fabrics also give higher moisture vapor and heat transmission. 
The hemp fabrics pure as well as union shows better moisture management property compared to other fabrics.

From thermal comfort point of view, pure unconventional fiber fabrics and their union fabrics with cotton give better performance value than $100 \%$ cotton fabric. Therefore, these fabrics can be considered more suitable for summer clothing applications.

THV of all pure unconventional fiber based fabrics and their respective union fabrics are either comparable or better than $100 \%$ cotton.

\section{Conflicts of Interest}

The authors declare no conflicts of interest regarding the publication of this paper.

\section{References}

[1] Mwaikambo, L. (2006) Review of the History, Properties and Application of Plant Fibres. African Journal of Science and Technology, 7, 121.

[2] Garbyal, R. (2015) Angora/Merino and Eri Silk: A New Union Woven Fabric for Fashion. Asian Journal of Home Science, 10, 437-441. https://doi.org/10.15740/HAS/AJHS/10.2/437-441

[3] Pamuk, O. (2008) Clothing Comfort Properties in Textile Industry. E-Journal of New World Sciences Academy, 3, 69-74.

[4] Behera, B.K. (2007) Comfort and Handle Behaviour of Linen-Blended Fabrics. Autex Research Journal, 7, 33-47.

[5] Pan, N., Yen, K.C., Zhao, S.T. and Yang, S.R. (1988) A New Approach to the Objective Evaluation of Fabric Handle from Mechanical Properties Part I: Objective Measure for Total Handle Nature of Fabric Handle and Problems of Evaluation. Textile Research Journal, 58, 438-443. https://doi.org/10.1177/004051758805800802

[6] Bajzík, V. (2016) Some Approaches to Objective Evaluation of Fabric Hand. World Journal of Textile Engineering and Technology, 2, 1-11.

[7] Behera, B.K. and Mishra, R. (2007) Comfort Properties of Non-Conventional Light Weight Worsted Suiting Fabrics. Indian Journal of Fibre \& Textile Research, 32, 72-79.

[8] Majumdar, A. and Pol, S.B. (2014) Low Stress Mechanical Properties of Fabrics Woven from Bamboo Viscose Blended Yarns. Fibers and Polymers, 15, 1985-1991. https://doi.org/10.1007/s12221-014-1985-y

[9] Behera, B.K. and Hari, P.K. (1994) Fabric Quality Evaluation by Objective Measurement. Indian Journal of Fibre \& Textile Research, 19, 168-171.

[10] Havlová, M. (2013) Air Permeability and Costructional Parameters of Woven Fabrics. Fibres \& Textiles in Eastern Europe, 98, 84-89.

[11] Özdemir, H. (2017) Thermal Comfort Properties of Clothing Fabrics Woven with Polyester/Cotton Blend Yarns. Autex Research Journal, 17, 135-141. https://doi.org/10.1515/aut-2016-0012

[12] Matusiak, M. and Sikorski, K. (2011) Influence of the Structure of Woven Fabrics on Their Thermal Insulation Properties. Fibres \& Textiles in Eastern Europe, 88, 46-53.

[13] Mitsu, M. and Masahiko, K. (1996) Objective Evaluation of Hand for Futon Cloth. Journal of the Textile Machinery Society of Japan, 42, 23-35.

https://doi.org/10.4188/jte1955.42.23 